\title{
Robotic Stepwise Synthesis of Hetero-Multinuclear Metal Oxo Clusters as Single-Molecule Magnets
}

\author{
Takuo Minato, Daniel Salley, Noritaka Mizuno, Kazuya Yamaguchi, Leroy Cronin,** and Kosuke Suzuki*
}

Cite This: J. Am. Chem. Soc. 2021, 143, 12809-12816

Read Online

ABSTRACT: An efficient stepwise synthesis method for discovering new heteromultinuclear metal clusters using a robotic workflow is developed where numerous reaction conditions for constructing heteromultinuclear metal oxo clusters in polyoxometalates (POMs) were explored using a custom-built automated platform. As a result, new nonanuclear tetrametallic oxo clusters $\left\{\mathrm{FeMn}_{4}\right\} \mathrm{Lu}_{2} \mathrm{~A}_{2}$ in $\mathrm{TBA}_{5}\left[\left(\mathrm{~A}-\alpha-\mathrm{SiW}_{9} \mathrm{O}_{34}\right)_{2} \mathrm{FeMn}_{4} \mathrm{O}_{2}\{\mathrm{Lu}-\right.$ $\left.\left.(\text { acac })_{2}\right\}_{2} \mathrm{~A}_{2}\right]\left(\mathrm{II}^{\mathrm{A}} ; \mathrm{A}=\mathrm{Ag}, \mathrm{Na}, \mathrm{K} ; \mathrm{TBA}=\right.$ tetra- $n$-butylammonium; acac = acetylacetonate) were discovered by the installation of diamagnetic metal cations $\mathrm{A}^{+}$into a paramagnetic $\left\{\mathrm{FeMn}_{4}\right\} \mathrm{Lu}_{2}$ unit in $\mathrm{TBA}_{7}\left[\left(\mathrm{~A}-\alpha-\mathrm{SiW}_{9} \mathrm{O}_{34}\right)_{2} \mathrm{FeMn}_{4} \mathrm{O}_{2}\left\{\mathrm{Lu}(\mathrm{acac})_{2}\right\}_{2}\right]$ (I). POMs II $^{\mathbf{A}}$ exhibited single-molecule magnet properties with the higher energy barriers for magnetization reversal $\left(\mathrm{II}^{\mathrm{Ag}}, 40.0 \mathrm{~K}\right.$; $\mathbf{I I}^{\mathrm{Na}}, 40.3$

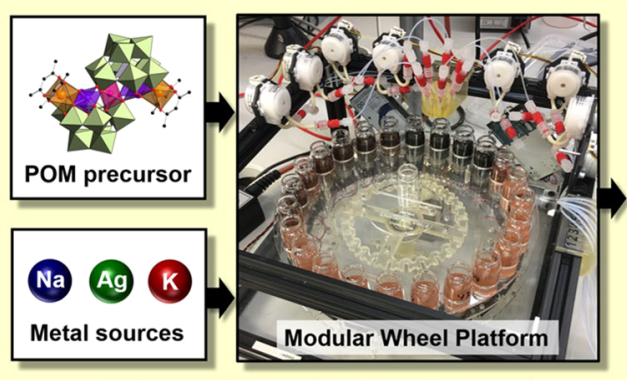

Automated stepwise synthesis of hetero-multinuclear metal oxo clusters

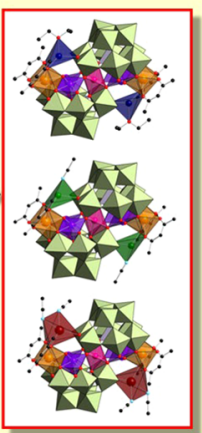

$\left.\mathrm{K} ; \mathrm{II}^{\mathrm{K}}, 26.7 \mathrm{~K}\right)$ compared with that of the parent $\mathrm{I}(19.7 \mathrm{~K})$. Importantly, these clusters with unique properties were constructed as designed by a step of the predictable sequential multistep reactions with the time-efficient platform.

\section{INTRODUCTION}

Over the past several decades, material scientists have tried to develop effective methods in response to the scientifically inspirational question posed by Richard P. Feynman: "What could the properties of materials be if we could really arrange the atoms the way we want?" In molecular synthetic chemistry, controlling physical and chemical properties of homo/heteromultinuclear metal clusters by precise structural arrangement is crucial ${ }^{2}$ because the combination, nuclearity, and coordination geometries of metal cations are closely correlated to the electronic and magnetic interactions between metal cations. ${ }^{3}$ From the viewpoint of constructing desired heteromultinuclear metal clusters, the stepwise synthesis method using a bottom-up approach has proven to be a powerful tool when compared with the one-step (usually onepot) synthesis method by serendipitous or empirical molecular assembly (Figure 1a). ${ }^{4}$ This is primarily due to the fact that stepwise synthesis enables the chemist to target desired structures using specifically designed multidentate ligands, allowing for the selection of specific metal sources at each step (Figure 1b). However, stepwise synthesis is a time-consuming method as the combinations of metal cations grow exponentially as the variety of metal cations available is increased. An additional difficultly is that unpredictable condensation/dissociation reactions of metal-containing species often occur due to flexibility in some multidentate organic ligands that lack bulky functional groups (Figure S1). ${ }^{5}$ Thus, the development of a time-efficient simple method applicable to dozens of reaction conditions in order to construct atomically designed heteromultinuclear metal clusters in a predictable system is required. ${ }^{6}$

Polyoxometalates (POMs) are a family of anionic molecular metal oxide clusters that exhibit diversity of structures, sizes, and physical and chemical properties. ${ }^{7}$ By utilizing lacunary POMs as robust, bulky multidentate inorganic ligands, numerous types of multinuclear metal and metal oxo clusters possessing unique catalytic, electronic, and magnetic properties have been synthesized. ${ }^{8,9}$ Recently, we have successfully synthesized heteromultinuclear metal oxo clusters possessing a wide variety of metal cations using lacunary POMs. ${ }^{9-e}$ In these reports, arranging the proper types of metal cations in the desired position was demonstrated by the stepwise synthesis method, showing the precise control of their coordination geometries and magnetic properties. These results indicated that lacunary POMs act as ideal multidentate ligands for constructing various types of heteromultinuclear metal clusters by a predictable stepwise synthesis method. However, it can still require a lot of time and effort to carry out screening of large areas of reaction parameter space in multistep synthesis. For this, we chose to take advantage of recent advances in

Received: June 14, 2021

Published: August 6, 2021 


\section{(a) One-step synthesis}

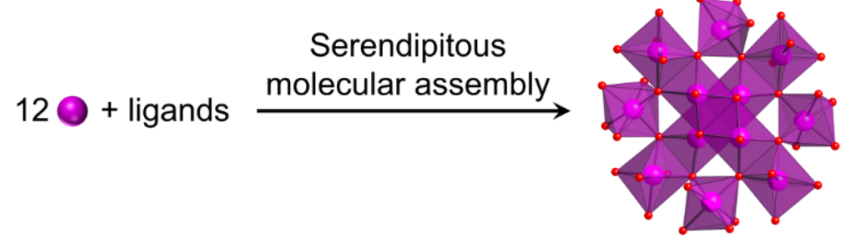

$\times$ Hard to predict structures beforehand

\section{(b) Stepwise synthesis}

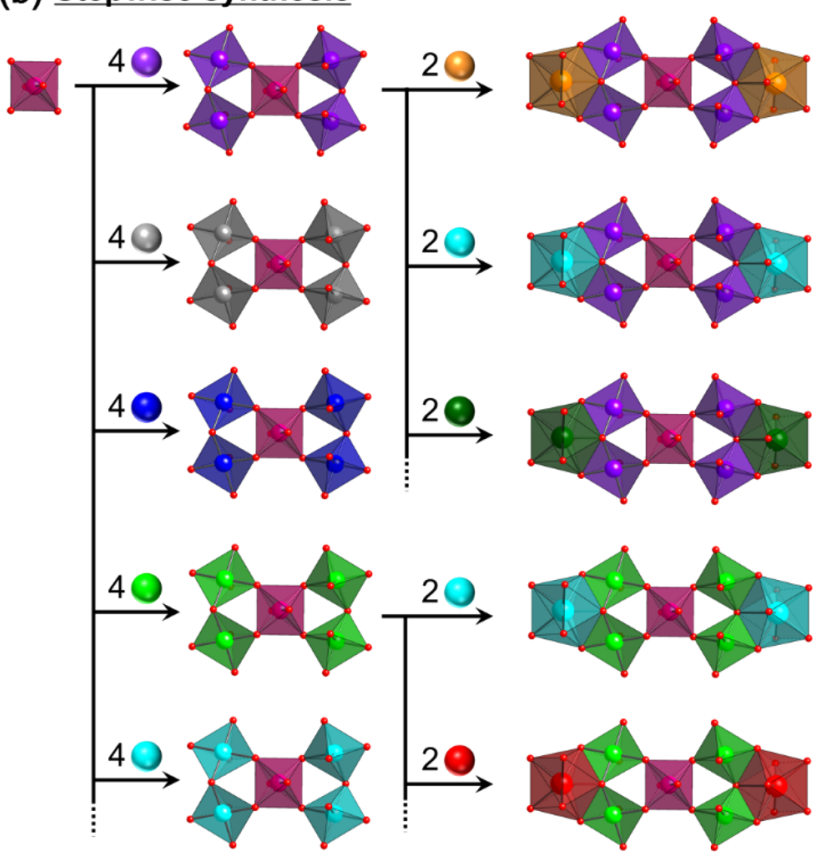

$\checkmark$ Easy to predict structures beforehand

$x$ Requiring time and effort

Figure 1. Schematics of (a) one-step and (b) stepwise synthesis methods for constructing heteromultinuclear metal clusters. Metal cations are represented by color spheres and polyhedra. Oxygen atoms are represented as small red spheres. Ligands are omitted for clarity.

approaches to the digitization of chemical synthesis and utilize a bespoke workflow to allow the stepwise synthesis of modular metal oxide clusters.

A number of automated synthesis methods have been reported in recent years for a variety of synthetic systems. ${ }^{10}$ More recently, a modular system for the combinatorial exploration of inorganic chemical space has been developed in the Cronin group at the University of Glasgow named the Modular Wheel Platform (MWP). ${ }^{11}$ This system has proven to be a powerful tool for automated screening of reaction conditions, leading to the discovery of gigantic and novel POMs. As this system was used for one-step, one-pot condensation reactions of metal sources, we envisioned expanding this methodology for stepwise synthesis using precursors, which should reduce time and effort for discovering new heteromultinuclear metal clusters.

Herein, we successfully demonstrate the efficient stepwise synthesis method for constructing heteromultinuclear metal oxo clusters within POMs by utilizing a simple automated platform. This facilitated the discovery of three new single- molecule magnets (SMMs) including the structure with the highest energy barrier for magnetization reversal $\left(U_{\text {eff }}\right)$ among the previously reported transition metal-containing POMs.

\section{RESULTS AND DISCUSSION}

In a stepwise synthesis method, to reduce time and effort for synthesizing new compounds and to discover unknown compounds efficiently, it is necessary to achieve (1) acceleration of established procedures, (2) examination of various synthesis conditions at the same time, and (3) optimization of the best synthesis and crystallization conditions in unestablished procedures (Figure 2). Importantly, screening processes of steps (2) and (3) are the bottlenecks to discover new compounds in a manual stepwise synthesis method even when structures of desired compounds are predictable. To demonstrate the efficient robotic stepwise synthesis method, a system of heteromultinuclear metal oxo clusters within trivacant lacunary POMs is chosen in this study because the above-mentioned three tasks can systematically be examined.

By utilizing $\mathrm{TBA}_{4}\left[\mathrm{~A}-\alpha-\mathrm{SiW}_{9} \mathrm{O}_{31}\left(\mathrm{H}_{2} \mathrm{O}\right)_{3}\right](\mathrm{TBA}=$ tetra- $n$ butylammonium $)^{12}$ as a multidentate inorganic ligand, we have developed the sequential synthesis method for constructing heteromultinuclear metal clusters, including $\mathrm{TBA}_{7} \mathrm{H}_{10}[(\mathrm{~A}-\alpha$ $\left.\left.\mathrm{SiW}_{9} \mathrm{O}_{34}\right)_{2} \mathrm{Fe}\right] \quad(\{\mathrm{Fe}\}), \quad \mathrm{TBA}_{7}\left[\left(\mathrm{~A}-\alpha-\mathrm{SiW}_{9} \mathrm{O}_{34}\right)_{2} \mathrm{FeMn}_{4}(\mathrm{OH})_{2}\right]$ $\left(\left\{\mathrm{FeMn}_{4}\right\}\right)$, and $\mathrm{TBA}_{7}\left[\left(\mathrm{~A}-\alpha-\mathrm{SiW}_{9} \mathrm{O}_{34}\right)_{2} \mathrm{FeMn}_{4} \mathrm{O}_{2}\{\mathrm{Lu}-\right.$ $\left.\left.(\text { acac })_{2}\right\}_{2}\right](\mathbf{I}$, acac $=$ acetylacetonate $) .{ }^{9 a-e}$ It takes about 1 week in each step to synthesize and characterize these clusters via stirring the solutions, isolation and crystallization of powder samples, and analyses by X-ray, IR, mass measurements, etc. using established synthesis methods (Figure 2), while it will take several weeks to months in order to examine the reactivity of the precursor with metal cations and to optimize synthesis and crystallization conditions in unestablished procedures, such as addition of various types of univalent metal cations into I (Figure 2). It should be noted that it took several months to establish the synthesis conditions of $\{\mathrm{Fe}\},\left\{\mathrm{FeMn}_{4}\right\}$, or $\mathbf{I}$.

Since the structure of $\mathbf{I}$ was controlled in an atomic level by the stepwise synthesis method, I possessed unique features applicable to the digitization of chemical synthesis. First, POM I possesses four pseudo vacant sites that can potentially react with a variety univalent metal cations, which enables us to predict accurately the possible structures (Figure S2). Second, to screen the various cation types and finally to vary the stoichiometric ratio of univalent metal cations to assess reactivity, which is important in an unestablished procedure. In addition, as POM I shows SMM properties, the effect of the types of installed diamagnetic metal cations on magnetic properties is also interesting in terms of "modular synthesis approach". ${ }^{9 \mathrm{~d}}$ Furthermore, since a series of heptanuclear trimetallic $\left\{\mathrm{M}^{1} \mathrm{M}_{4}^{2}\right\} \mathrm{M}^{3}{ }_{2}$ clusters in POMs can be synthesized by established three-step reactions of $\mathrm{TBA}_{4}[\mathrm{~A}-\alpha-\mathrm{Si}$ $\left.\mathrm{W}_{9} \mathrm{O}_{31}\left(\mathrm{H}_{2} \mathrm{O}\right)_{3}\right]$ with metal cations, automated synthesis of numerous types of heteromultinuclear metal oxo clusters in POMs as designed would be possible by expanding the methodology in this study.

First, we examined the one-pot stepwise synthesis of I from $\{\mathrm{Fe}\}$ without isolation of the intermediate structure $\left\{\mathrm{FeMn}_{4}\right\}$ to assess whether the system was applicable to the MWP and to accelerate the established procedures (Figure 2). Into a 1,2dichloromethane solution of I ( $4 \mathrm{mM}, 2 \mathrm{~mL}), 1,2$-dichloromethane solutions of $\mathrm{Mn}(\mathrm{acac})_{3}(16 \mathrm{mM}, 0.25 \mathrm{~mL})$ and $\mathrm{Lu}(\mathrm{acac})_{3}(16 \mathrm{mM}, 0.25 \mathrm{~mL})$ were added in this order and a 


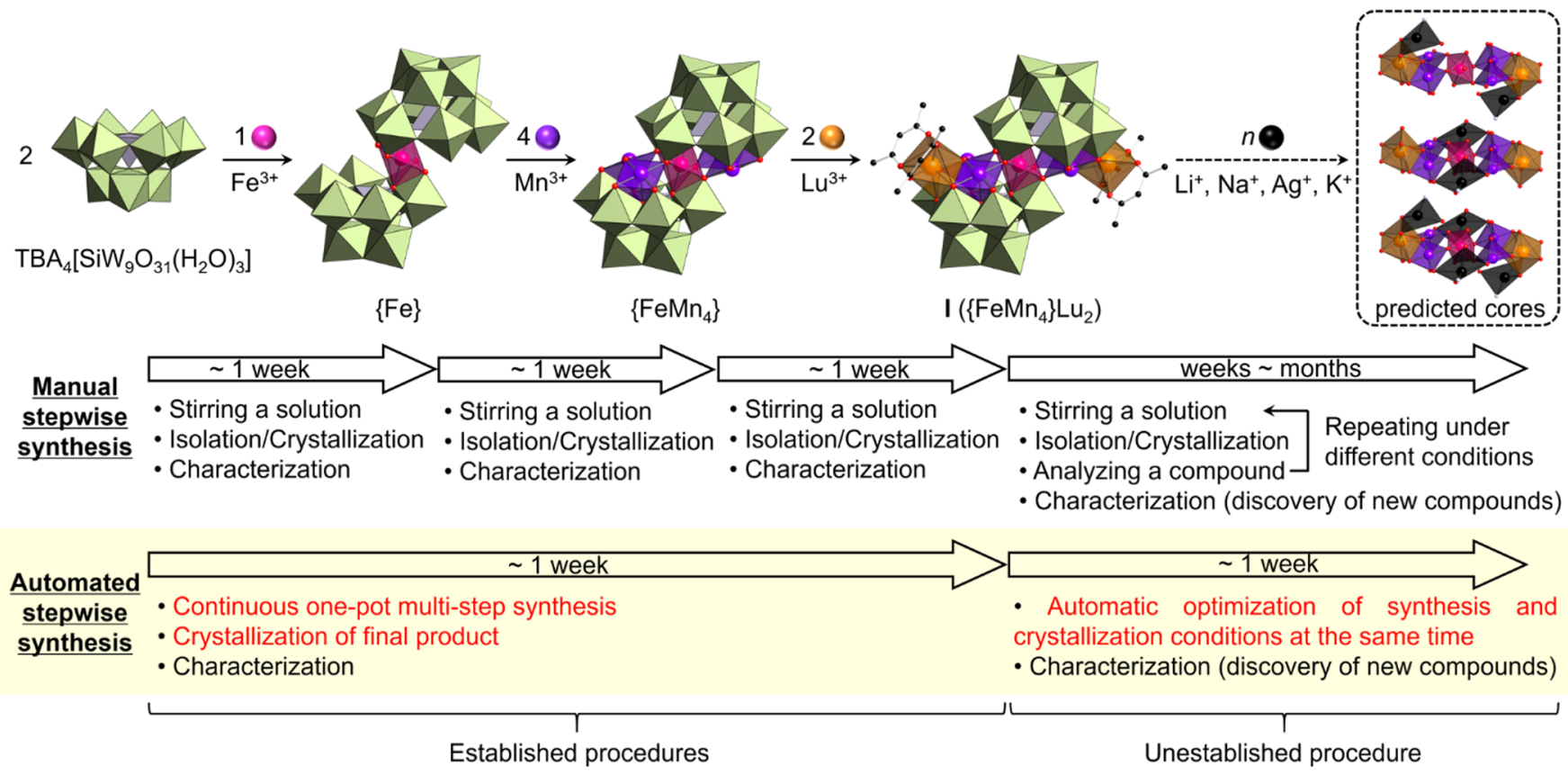

Figure 2. Schematic of manual and automated stepwise synthesis of $\mathbf{I}$. Required time in each step are shown as bold arrows. Required tasks in each step are shown under the allows, where tasks in red can be automated. The atoms are represented by polyhedra and spheres: $\mathrm{Si}$, gray; $\mathrm{W}$, light green; Fe, pink; $\mathrm{Mn}$, purple; Lu, orange; and A, black. Oxygen and carbon atoms are represented by small red and black spheres, respectively.

stepwise manner. The electrospray ionization mass measurement of the synthetic solution in each step showed sets of signals assignable to $\{\mathrm{Fe}\},\left\{\mathrm{FeMn}_{4}\right\}$, or I, indicating that the reaction proceeded without isolation of the intermediate structure (Figure S3). These results illustrated that the continuous one-pot multistep synthesis of I was possible, thus indicating that this system would be directly applicable to the MWP. Since it was not necessary to isolate and characterize the intermediate structures, one-pot stepwise synthesis of I could surely reduce time and effort for the established synthesis. More importantly, by changing the types of metal sources, various types of heteromultinuclear metal clusters, including $\left\{\mathrm{M}^{1} \mathrm{M}^{2}{ }_{4}\right\} \mathrm{M}^{3}{ }_{2}\left(\mathrm{M}^{1}=\mathrm{V}^{3+}, \mathrm{Cr}^{3+}, \mathrm{Mn}^{3+}, \mathrm{Fe}^{3+}\right.$, $\mathrm{Co}^{2+}, \mathrm{Ni}^{2+}, \mathrm{Cu}^{2+}, \mathrm{Ga}^{3+} ; \mathrm{M}^{2}=\mathrm{Mn}^{3+}, \mathrm{Cu}^{2+} ; \mathrm{M}^{3}=\mathrm{Gd}^{3+}, \mathrm{Dy}^{3+}$, $\mathrm{Lu}^{3+}$, etc.), can be synthesized automatically at the same time within a few days, which enables to accelerate screening processes of the established stepwise synthesis method (Figures 1b, 2).

Next, we demonstrated the MWP-assisted stepwise synthesis utilizing I to solve the main bottleneck for discovering new compounds in the unestablished procedure. To achieve the automated stepwise synthesis using POM I, it is crucial to control synthesis conditions, including (1) temperature, (2) reaction time, and (3) stirring speed, over all reaction vessels. In addition to the environmental conditions, the precise control of screening parameters, including (4) concentration of POM solution, (5) types and (6) equivalents of added metal cations, and (7) amount of poor solvent against synthetic solution for crystallization, are also important to assess reactivity. Therefore, we utilized the MWP where these parameters can be digitized and accurately delivered to our reaction vessels. The system itself uses in house software, written in Python to control hardware via Arduino to run the operations of the synthesis. ${ }^{11}$ The MWP-assisted screening was attempted using the following stock solutions: acetonitrile, acetonitrile solution of $\mathbf{I}(8.32 \mathrm{mM})$, acetonitrile solution of
$\operatorname{AOTf}(\mathrm{A}=\mathrm{Li}, \mathrm{Na}, \mathrm{K}, \mathrm{Ag} ; 50 \mathrm{mM}$ ), and diethyl ether (poor solvent) (Figure 3 ). The volume of each solution was programmed as follows: The concentration of $\mathbf{I}$ in the synthetic solution was set to 10,20 , and $30 \mathrm{mg} / \mathrm{mL}$, and the

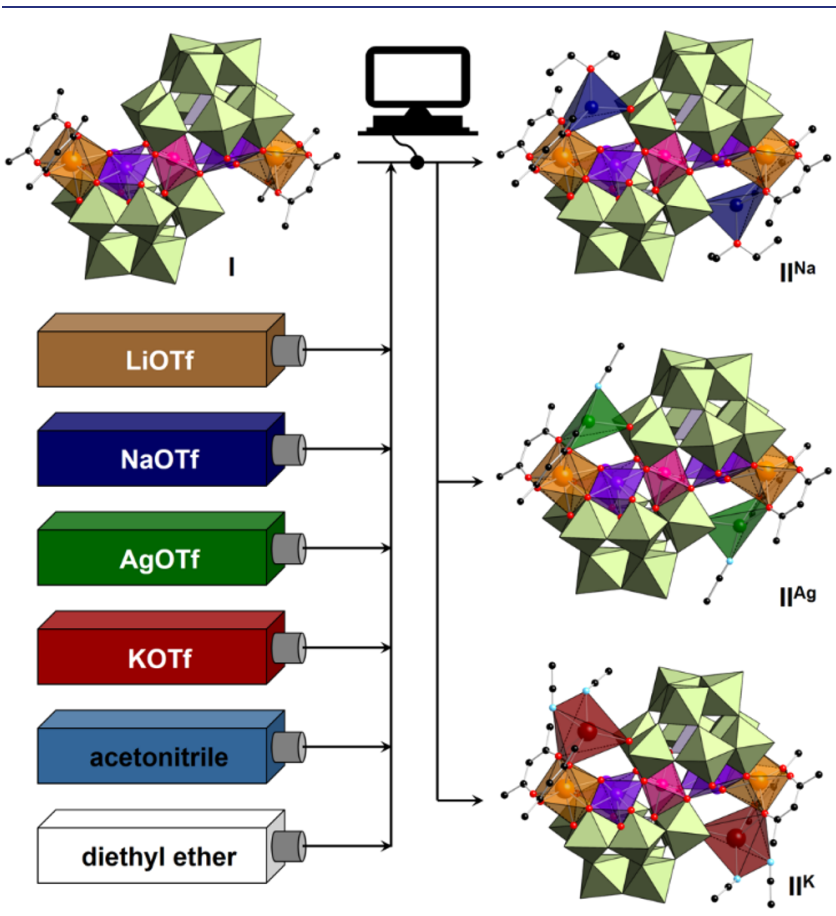

Figure 3. Schematic of the MWP-assisted stepwise synthesis of $\mathbf{I I}^{\mathrm{A}}$ using precursor $\mathrm{I}$. The atoms are represented by polyhedra and spheres: C, black; N, light blue; O, red; Si, gray; W, light green; Fe, pink; $\mathrm{Mn}$, purple; $\mathrm{Lu}$, orange; $\mathrm{Ag}$, green; $\mathrm{Na}$, blue; and $\mathrm{K}$, dark red. Color boxes represent stock solutions where pumps were controlled by Arduino Mega 2560/RAMPs boards via in house developed Python code. 
equivalents of AOTf with respect to I was set to 1, 2, 3, 4, 5, and 6, resulting in 72 reaction conditions (Table S1). It should be noted that equivalents of AOTf are important parameters even in the MWP-assisted stepwise synthesis, because we cannot control the types of products and thus deduce the best synthesis conditions in unestablished procedures although three possible structures can be predicted ahead of time (Figures 2, S2). Then, the programmed MWP performed the following sequence with constant stirring: (1) addition of POM solution, (2) dilution with acetonitrile, (3) addition of AOTf solution, (4) dilution to final $2 \mathrm{~mL}$ of total volume with acetonitrile, (5) stirring for $4 \mathrm{~h}$, and (6) addition of diethyl ether for the crystallization. Since the reaction vessels were arranged in a circle, each batch can be moved by rotating the circular platform to perform every reaction automatically (Figure 4). Notably, it took approximately only $60 \mathrm{~min}$ to

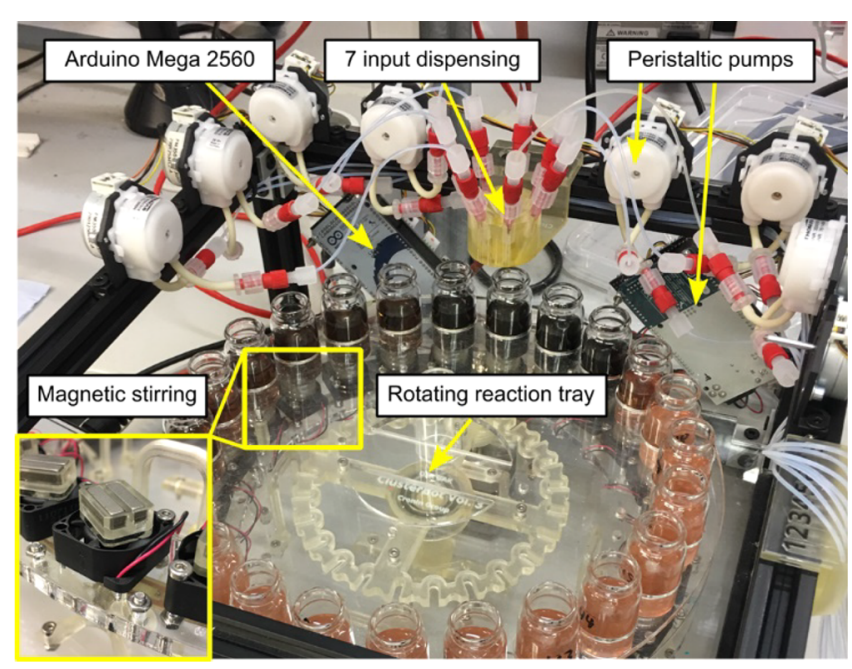

Figure 4. Photograph of the MWP used in this study. ${ }^{11}$

finish all reaction conditions before the 4-h stirring step, and all we had to do was to push the enter key once, showing a drastic reduction of time and effort to explore large areas of reaction parameter space in an unestablished reaction step (Figure 2).

As a result, the MWP created many crystals although powder precipitations were obtained in most reactions containing $\geq 3$ equivalents of metal cations, indicating that all of four vacant sites of I could not react with metal cations simultaneously, and cation exchange reactions with $\mathrm{TBA}^{+}$might occur (Figure S4). In addition, when adding LiOTf, crystals could be obtained by only one reaction condition, and quality of crystals was too poor to reveal the crystal structure, indicating that ionic radius of $\mathrm{A}^{+}$was important factor to be installed into the vacant sites of $\mathbf{I}$ and crystallized. Furthermore, the size of crystals tended to be large with increasing the concentration of I. These results illustrated that the optimization of unestablished synthesis and crystallization conditions was easily performed by using the MWP although this process was quite often a bottleneck in a manual synthesis approach (Figure 2).

When adding AgOTf, NaOTf, or KOTf, the single crystals suitable for the X-ray crystallographic analysis were obtained. The X-ray crystallographic analyses successfully revealed that each product possessed a nonanuclear tetrametallic $\left\{\mathrm{FeMn}_{4}\right\}$ $\mathrm{Lu}_{2} \mathrm{~A}_{2}$ cluster (Table S2, Figures 3, S5b-d). These three anion structures were essentially isostructural with each other except for the differences in the types of $\mathrm{A}^{+}$and coordinated ligands on $\mathrm{A}^{+}$. As expected from the screening of crystallization, two of four vacant sites of $I$ were reacted with $\mathrm{A}^{+}$. The bond valence sum values indicate that the respective valences of $\mathrm{W}, \mathrm{Si}, \mathrm{Fe}$, $\mathrm{Mn}, \mathrm{Lu}$, and $\mathrm{A}$ are $+6,+4,+3,+3,+3$, and +1 (Tables S3$\mathrm{S} 5)$. In $\mathrm{II}^{\mathrm{A}}$, two $[\mathrm{A} \text { (solvents) }]^{+}$units (solvents $=\mathrm{CH}_{3} \mathrm{CN}$ or $\mathrm{C}_{2} \mathrm{H}_{5} \mathrm{OC}_{2} \mathrm{H}_{5}$ ) were installed so as to bridge $\mathrm{Lu}^{3+}$ and the $[\mathrm{A}-\alpha-$ $\left.\mathrm{SiW}_{9} \mathrm{O}_{34}\right]^{10-}$ unit. Interestingly, one of the six-membered chelate rings of acac ligands coordinated to $\mathrm{Lu}^{3+}$ in $\mathrm{II}^{\mathrm{Ag}}$ stacked with the chelate ring of neighbor anion, resulting in the alignment of the anions in the same direction (Figures S6, S7). By installing the diamagnetic metal cations into $I$, the coordination geometries of $\left\{\mathrm{FeMn}_{4}\right\} \mathrm{Lu}_{2}$ were slightly changed; an increase in $\mathrm{Fe}-\mathrm{O}-\mathrm{Mn}$ bond angles and a decrease in $\mathrm{Mn}-$ $\mathrm{O}-\mathrm{Mn}$ bond angles were observed (Table S6). As the ionic radii of $\mathrm{A}^{+}$became larger, the distances between $\mathrm{A}^{+}$and the bridging oxygen atom of $\mathrm{Mn}-\mathrm{O}-\mathrm{Mn}$ became longer. The cold-spray ionization mass measurements of $\mathrm{II}^{\mathrm{A}}$ in acetonitrile supported that these structures were selectively synthesized (Figure S8). On the basis of all the above-mentioned results, elemental analyses, and thermogravimetric differential thermal analysis data, $\mathbf{I I}^{\mathbf{A g}}, \mathbf{I I}^{\mathrm{Na}}$, and $\mathbf{I I}^{\mathrm{K}}$ were proposed to have formulas of $\mathrm{TBA}_{5}\left[\left(\mathrm{~A}-\alpha-\mathrm{SiW}_{9} \mathrm{O}_{34}\right)_{2} \mathrm{FeMn}_{4} \mathrm{O}_{2}\left\{\mathrm{Lu}(\mathrm{acac})_{2}\right\}_{2} \mathrm{Ag}_{2}\right]$. $4 \mathrm{H}_{2} \mathrm{O} \cdot \mathrm{CH}_{3} \mathrm{CN}, \quad \mathrm{TBA}_{5}\left[\left(\mathrm{~A}-\alpha-\mathrm{SiW}_{9} \mathrm{O}_{34}\right)_{2} \mathrm{FeMn}_{4} \mathrm{O}_{2}\{\mathrm{Lu}-\right.$ $\left.\left.(\text { a c a c })_{2}\right\}_{2} \mathrm{Na}_{2}\right] \cdot 13 \mathrm{H}_{2} \mathrm{O}$, and TBA 5 [ ( A - $\alpha-$ $\left.\left.\mathrm{SiW}_{9} \mathrm{O}_{34}\right)_{2} \mathrm{FeMn}_{4} \mathrm{O}_{2}\left\{\mathrm{Lu}(\mathrm{acac})_{2}\right\}_{2} \mathrm{~K}_{2}\right] \cdot 9 \mathrm{H}_{2} \mathrm{O}$, respectively. These results clearly illustrated that the MWP-assisted screening successfully discovered three new heteromultinuclear metal oxo clusters as designed.

In order to investigate the magnetic properties of $\mathrm{II}^{\mathrm{A}}$, magnetic susceptibility measurements were performed. The direct current magnetic susceptibilities of $\mathbf{I}$ and $\mathbf{I I}^{\mathrm{A}}$ under $0.1 \mathrm{~T}$ showed the $\chi T$ values of $10.80(\mathbf{I}), 11.54\left(\mathbf{I I}^{\mathrm{Ag}}\right), 13.77\left(\mathrm{II}^{\mathrm{Na}}\right)$, and $12.23 \mathrm{~cm}^{3} \mathrm{~K} \mathrm{~mol}^{-1}\left(\mathrm{II}^{\mathrm{K}}\right)$ at $300 \mathrm{~K}$, respectively (Figure S9). These values are significantly lower than the sum of the spin-only values of one high-spin $\mathrm{Fe}^{3+}$ and four high-spin $\mathrm{Mn}^{3+}$ $\left(16.38 \mathrm{~cm}^{3} \mathrm{~K} \mathrm{~mol}^{-1}\right)$, which is likely due to the antiferromagnetic interactions. The $\chi T$ values of $\mathbf{I}$ gradually decreased with decreasing temperature, while those of $\mathbf{I I}^{\mathbf{A}}$ gradually decreased with decreasing temperature and then increased below about $50 \mathrm{~K}$, and reached to the values of 13.38 $\left(\mathrm{II}^{\mathrm{Ag}}, 2.9 \mathrm{~K}\right), 12.14\left(\mathrm{II}^{\mathrm{Na}}, 4.9 \mathrm{~K}\right)$, and $8.83\left(\mathrm{II}^{\mathrm{K}}, 9.68 \mathrm{~K}\right) \mathrm{cm}^{3} \mathrm{~K}$ $\mathrm{mol}^{-1}$, respectively. These results indicated that the spin ground states of $\mathbf{I I}^{\mathbf{A}}$ were enhanced. The $M$ vs $H$ data showed that the magnetization saturated at values of $9.1\left(\mathrm{II}^{\mathrm{Ag}}\right), 7.2$ $\left(\mathbf{I I}^{\mathrm{Na}}\right)$, and $7.0\left(\mathbf{I I}^{\mathrm{K}}\right) N \mu_{B}$, also supporting the larger spin ground states of $\mathbf{I I}^{\mathrm{A}}$ compared with that of $\mathbf{I}\left(2.8 N \mu_{B}\right)$ (Figure S10).

The alternating current magnetic susceptibility measurements for $\mathrm{II}^{\mathrm{A}}$ showed considerable temperature and frequencydependent $\chi^{\prime}$ and $\chi^{\prime \prime}$ even under a zero external dc field, indicating the slow relaxation of magnetization characteristic for SMMs (Figure $5 a-c, S 11$ ). The Arrhenius plots showed that the values of $U_{\text {eff }}$ in $\mathrm{II}^{\mathrm{A}}$ were $40.0\left(\mathrm{II}^{\mathrm{Ag}}\right), 40.3\left(\mathrm{II}^{\mathrm{Na}}\right)$, and $26.7 \mathrm{~K}\left(\mathrm{II}^{\mathrm{K}}\right)$, respectively (Figure $5 \mathrm{~d}$ ). By installing $\mathrm{A}^{+}$into the $\left\{\mathrm{FeMn}_{4}\right\} \mathrm{Lu}_{2}$ unit in $\mathbf{I}$, the energy barriers of $\mathbf{I I}^{\mathbf{A}}$ were doubled and significantly enhanced in comparison with that of $\mathbf{I}\left(U_{\text {eff }}=\right.$ $19.7 \mathrm{~K}) .{ }^{9 \mathrm{c}}$ It is noteworthy that the energy barrier of $\mathrm{II}^{\mathrm{Na}}\left(U_{\text {eff }}\right.$ $=40.3 \mathrm{~K})$ is the highest among those of the previously reported transition metal-containing POMs (Table S7). ${ }^{9,13}$ In order to discover a SMM with high $U_{\text {eff }}$, scientists have been taken a lot of time and effort to synthesize molecular clusters under various synthesis conditions, while we could automati- 

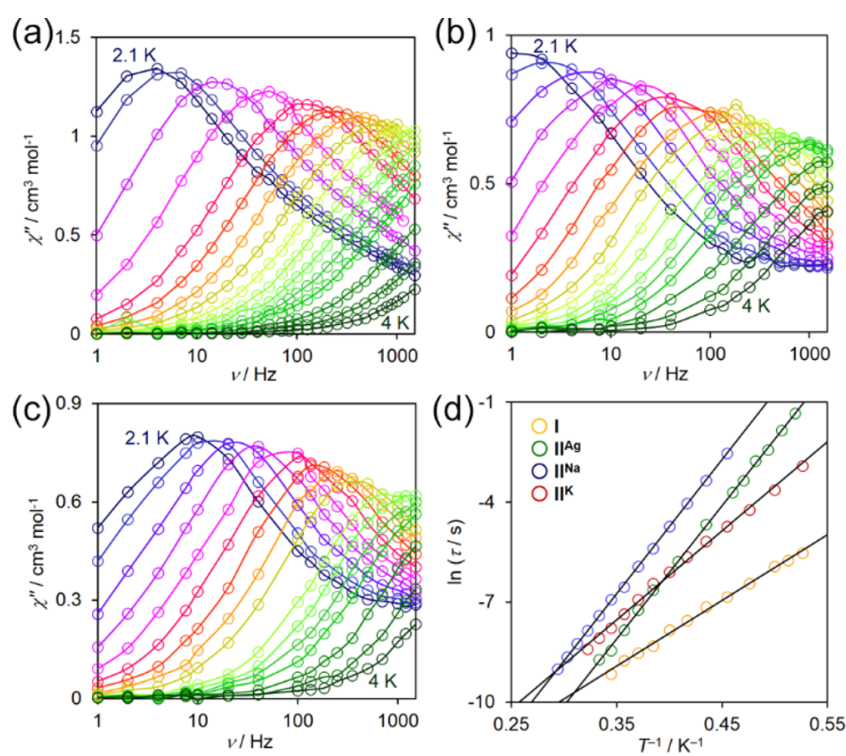

Figure 5. Frequency dependences of $\chi^{\prime \prime}$ for (a) $\mathrm{II}^{\mathrm{Ag}}$, (b) $\mathrm{II}^{\mathrm{Na}}$, and (c) $\mathrm{II}^{\mathrm{K}}$ under zero external dc fields. (d) Plots of relaxation time $(\tau)$ versus $T^{-1}$ for $\mathrm{II}^{\mathrm{A}}$. The solid lines represent the best fit with the Arrhenius law $\left(\ln \tau\left(\tau=\tau_{0} \exp \left(U_{\text {eff }} / k_{B} T\right)\right)\right.$ vs $\left.T^{-1}\right)$ at the thermally activated regime.

cally find $\mathrm{II}^{\mathrm{Na}}$ by a simple robotic stepwise synthesis method even in an unestablished procedure.

\section{CONCLUSION}

In conclusion, the MWP-assisted stepwise synthesis successfully lead to the discovery of three new POMs with high $U_{\text {eff }}$ values. Importantly, the discoveries made in this study were achieved not by serendipitous molecular assembly using mononuclear metal sources but by a series of predictable sequential multistep reactions. The structure of the precursor I was maintained after the introduction of $\mathrm{A}^{+}$, which enabled us to construct atomically designed heteromultinuclear metal clusters in a predictable way regardless of established or unestablished procedures. Therefore, it is our hope that the robotic stepwise synthesis strategy and the use of time and resource efficient automated platforms can be applied in various fields requiring precise structural arrangement of multinuclear metal oxo and metallic clusters, both to increase productivity and synthetic accuracy in these areas.

\section{EXPERIMENTAL SECTION}

Materials and Instruments. Acetonitrile (Kanto Chemical), diethyl ether (Kanto Chemical), 1,2-dichloroethane (Kanto Chemical), $\mathrm{Mn}(\mathrm{acac})_{3}$ (TCI), Lu(acac) ${ }_{3}$ (Aldrich), LiOTf (Alfa Aesar), NaOTf (TCI and Alfa Aesar), KOTf (Kanto Chemical and Alfa Aesar), and AgOTf (Aldrich) were used as received. $\mathrm{TBA}_{7} \mathrm{H}_{10}[(\mathrm{~A}-\alpha$ $\left.\left.\mathrm{SiW}_{9} \mathrm{O}_{34}\right)_{2} \mathrm{Fe}\right]^{9 a}$ was synthesized according to the reported procedure. $\mathrm{TBA}_{7}\left[\left(\mathrm{~A}-\alpha-\mathrm{SiW}_{9} \mathrm{O}_{34}\right)_{2} \mathrm{FeMn}_{4} \mathrm{O}_{2}\left\{\mathrm{Lu}(\mathrm{acac})_{2}\right\}_{2}\right](\mathrm{I})^{9 \mathrm{c}}$ was synthesized according to the reported procedure but recrystallized directly from the synthetic solution by addition of diethyl ether. IR spectra were measured on JASCO FT/IR-4100 using $\mathrm{KBr}$ disks. Cold-spray ionization (CSI) mass spectra were recorded on JEOL JMS-T100CS. Electrospray ionization (ESI) mass spectra were recorded on Agilent 6230 TOF LC/MS. Thermogravimetric and differential thermal analyses (TG-DTA) were performed on Rigaku Thermo plus TG 8120. ICP-AES analyses for $\mathrm{Fe}, \mathrm{Mn}, \mathrm{Lu}, \mathrm{Ag}, \mathrm{Si}$, and $\mathrm{W}$ were performed with Shimadzu ICPS-8100. Polarized Zeeman AAS analyses for $\mathrm{Na}$ and $\mathrm{K}$ were performed with Hitachi ZA3000. Elemental analyses were performed on Elementar vario MICRO cube (for $\mathrm{C}, \mathrm{H}$, and $\mathrm{N}$ ) at the Elemental Analysis Center of School of Science of the University of Tokyo.

X-ray Crystallography. Diffraction measurements were made on a Rigaku MicroMax-007 Saturn 724 CCD detector with graphic monochromated Mo $\mathrm{K} \alpha$ radiation $(\lambda=0.71069 \AA, 50 \mathrm{kV}, 24 \mathrm{~mA})$ at $123 \mathrm{~K}$, Bruker Apex II Quasar CCD detector using Mo K $\alpha$ radiation $(\lambda=0.71073 \AA, 50 \mathrm{kV}, 1 \mathrm{~mA})$ at $150 \mathrm{~K}$, or Bruker D8 VENTURE PHOTON II detector using Mo $\mathrm{K} \alpha$. The data were collected and processed using CrystalClear ${ }^{14}$ and CrysAlis ${ }^{\mathrm{PRO}} .{ }^{15}$ Neutral scattering factors were obtained from the standard source. In the reduction of data, Lorentz and polarization corrections were made. The structural analyses were performed using CrystalStructure ${ }^{16}$ and WinGX.17 All structures were solved by SHELXS (direct methods) and refined by SHELXL-2018/3. ${ }^{18}$ The highly disordered TBA cations and solvents in $\mathbf{I}$ and $\mathbf{I I}^{\mathbf{A}}$ were omitted by use of SQUEEZE program. ${ }^{19}$ The metal atoms $(\mathrm{Fe}, \mathrm{Mn}, \mathrm{Lu}, \mathrm{Na}, \mathrm{K}, \mathrm{Ag}, \mathrm{Si}$, and $\mathrm{W})$ and oxygen atoms in the POM frameworks, the organic ligands, solvents of crystallization, and TBA cations were refined anisotropically. CCDC-1570010 (I), $-1570008\left(\mathbf{I I}^{\mathrm{Ag}}\right),-1570009\left(\mathbf{I I}^{\mathrm{Na}}\right)$, and $-1570011\left(\mathbf{I I}^{\mathrm{K}}\right)$ contain the supplementary crystallographic data for this paper. The data can be obtained free of charge via www.ccdc.cam.ac.uk/conts/retrieving. html (or from the Cambridge Crystallographic Data Centre, 12, Union Road, Cambridge CB2 1EZ, UK; Fax: (+44) 1223-336-033; or deposit@ccdc.cam.ac.uk).

Bond Valence Sum (BVS) Calculations. The BVS values were calculated by the expression for the variation of the length $r_{i j}$ of a bond between two atoms $i$ and $j$ in observed crystal with valence $V_{i}$

$$
V_{i}=\sum_{j} \exp \left(\frac{r_{0}^{\prime}-r_{i j}}{B}\right)
$$

where $B$ is constant equal to $0.37 \AA$ and $r^{\prime}{ }_{0}$ is bond valence parameter for a given atom pair. ${ }^{20}$

Magnetic Susceptibilities. Magnetic susceptibilities of polycrystalline samples were measured on Quantum Design MPMS-XL7. Direct current (dc) magnetic susceptibility measurements were carried out between 1.9 and $300 \mathrm{~K}$ under $0.1 \mathrm{~T}$ magnetic field. Diamagnetic corrections were applied by the diamagnetisms of the sample holder and $\mathrm{TBA}_{46}\left[\mathrm{~A}-\alpha-\mathrm{SiW}_{9} \mathrm{O}_{31}\left(\mathrm{H}_{2} \mathrm{O}\right)_{3}\right] \cdot 2 \mathrm{H}_{2} \mathrm{O} .{ }^{12}$ Alternating current (ac) magnetic susceptibility measurements were carried out under zero dc field and the $3.96 \times 10^{-4} \mathrm{~T}$ ac oscillating field.

General Procedure for Synthesis of Hetero-Multinuclear Metal Clusters Using MWP. All reactions were carried out using the following procedures: Stock acetonitrile solutions of $\mathbf{I}(8.32 \mathrm{mM})$ and AOTf $(50 \mathrm{mM})$ were prepared and connected to the inlets for the programmable pumps. Acetonitrile solution of $\mathbf{I}(a \mathrm{~mL})$ was pumped to the reaction vessel with stirring approximately $600 \mathrm{rpm}$, followed by addition of acetonitrile $(b \mathrm{~mL})$, acetonitrile solution of AOTf $(c$ $\mathrm{mL})$, and acetonitrile $(d \mathrm{~mL})$ in this order. Total volume of each reaction solution was brought to $2 \mathrm{~mL}(a+b+c+d=2)$. Stock solution dispensing flow rate was $4 \mathrm{~mL} / \mathrm{min}$. During the reaction, the vessels were capped manually. After stirring for $4 \mathrm{~h}$, diethyl ether was pumped by entering specific amount of volume until the reaction solution became cloudy, followed by immediate filtration. After 2 days, crystals appeared in the following conditions: $7^{\mathrm{Li}}, 1^{\mathrm{Na}}, 2^{\mathrm{Na}}, 7^{\mathrm{Na}}$ $13^{\mathrm{Na}}, 14^{\mathrm{Na}}, 1^{\mathrm{Ag}}, 2^{\mathrm{Ag}}, 7^{\mathrm{Ag}}, 8^{\mathrm{Ag}}, 9^{\mathrm{Ag}}, 13^{\mathrm{Ag}}, 14^{\mathrm{Ag}}, 1^{\mathrm{K}}, 2^{\mathrm{K}}, 7^{\mathrm{K}}, 8^{\mathrm{K}}, 13^{\mathrm{K}}$, and $14^{\mathrm{K}}$ (Table S1). The structures of these crystals were confirmed by Xray crystallographic analyses, indicating that each compound possess two $\mathrm{A}^{+}$at the pseudo vacant sites between POM framework and $\mathrm{Lu}^{3+}$ regardless of the equivalent of AOTf. The syntheses of these heteromultinuclear metal clusters were reproducible by the procedures included below.

The platform used to perform these procedures was developed in the Cronin group at the University of Glasgow. The platform was published in 2020. ${ }^{11}$ Full details of the platform can be found in the Supporting Information of that previous work, including the bill of materials and instructions for the control software and construction of the platform. For this work, a summary of the platform is included here. The unit is constructed from custom 3D printed/laser cut parts and commercially available components. The control software was 
designed and written in-house using Python. Control of all functions was achieved via Arduino Mega/RAMPs microcontroller boards using this software that served to interface the Arduino controlled devices directly to a simple Python code.

Synthesis and Characterization of TBA $[(A-\alpha-$ $\left.\left.\mathrm{SiW}_{9} \mathrm{O}_{34}\right)_{2} \mathrm{FeMn} \mathrm{O}_{4} \mathrm{O}_{2}\left\{\mathrm{Lu}\left(\mathrm{C}_{5} \mathrm{H}_{7} \mathrm{O}_{2}\right)_{2}\right\}_{2} \mathrm{Ag}_{2}\right] \cdot 4 \mathrm{H}_{2} \mathrm{O} \cdot \mathrm{CH}_{3} \mathrm{CN}$ (II ${ }^{\mathrm{Ag}}$ ). To an acetonitrile solution $(1.5 \mathrm{~mL})$ of $\mathbf{I}(62.2 \mathrm{mg}, 8.6 \mu \mathrm{mol})$, AgOTf ( $4.4 \mathrm{mg}, 17.3 \mu \mathrm{mol}$ ) was added, and the resulting solution was stirred for $4 \mathrm{~h}$ at room temperature $\left(\mathrm{ca} .20^{\circ} \mathrm{C}\right)$. Then, diethyl ether $(4.4 \mathrm{~mL})$ was added to the solution, and the solution was filtered off. The brown crystals of $\mathbf{I I}^{\mathrm{Ag}}$ suitable for X-ray crystallographic analysis were obtained after 1 day ( $34.8 \mathrm{mg}, 57 \%$ yield based on I). IR ( $\mathrm{KBr}$ pellet): 2963, 2875, 1630, 1524, 1484, 1463, 1402, 1384, 1269, 1154, 1107, 1016, 962, 938, 890, 791, 752, 634, 538, 387, 368, 349, 333, 323, 313, $301,287,282,275,258,254 \mathrm{~cm}^{-1}$; positive ion MS (CSI, acetonitrile): $\mathrm{m} / \mathrm{z} 3710$ (calcd. 3710.1 ) $\left[\mathrm{TBA}_{7} \mathrm{Si}_{2} \mathrm{~W}_{18} \mathrm{O}_{70} \mathrm{FeMn}_{4} \mathrm{Lu}_{2}(\mathrm{acac})_{4} \mathrm{Ag}_{2}\right]^{2+}, 7178$ (calcd. 7177.7) $\left[\mathrm{TBA}_{6} \mathrm{Si}_{2} \mathrm{~W}_{18} \mathrm{O}_{70} \mathrm{FeMn}_{4} \mathrm{Lu}_{2}(\mathrm{acac})_{4} \mathrm{Ag}_{2}\right]^{+}$; elemental analysis calcd (\%) for $\mathrm{TBA}_{5}\left[\left(\mathrm{SiW}_{9} \mathrm{O}_{34}\right)_{2} \mathrm{FeMn}_{4} \mathrm{O}_{2}\left\{\mathrm{Lu}(\mathrm{acac})_{2}\right\}_{2} \mathrm{Ag}_{2}\right] \cdot 4 \mathrm{H}_{2} \mathrm{O} \cdot \mathrm{CH}_{3} \mathrm{CN}$ $\left(\mathrm{C}_{102} \mathrm{H}_{21} \mathrm{Ag}_{2} \mathrm{FeLu}_{2} \mathrm{Mn}_{4} \mathrm{~N}_{6} \mathrm{O}_{82} \mathrm{Si}_{2} \mathrm{~W}_{18}\right), \mathrm{C}$ 17.38, H 3.13, N 1.19, Si 0.80, W 46.95, Fe 0.79, Mn 3.12, Lu 4.96, Ag 3.06; found, C 17.37, H 3.18, N 1.21, Si 0.77, W 46.66, Fe 0.73, Mn 2.63, Lu 4.86, Ag 3.01. Synthesis and Characterization of $\mathrm{TBA}_{5}[(\mathrm{~A}-\alpha-$ $\left.\left.\mathrm{SiW}_{9} \mathrm{O}_{34}\right)_{2} \mathrm{FeMn}_{4} \mathrm{O}_{2}\left\{\mathrm{Lu}\left(\mathrm{C}_{5} \mathrm{H}_{7} \mathrm{O}_{2}\right)_{2}\right\}_{2} \mathrm{Na}_{2}\right] \cdot 13 \mathrm{H}_{2} \mathrm{O}\left(\mathrm{II}^{\mathrm{Na}}\right)$. To an acetonitrile solution $(1 \mathrm{~mL})$ of $\mathbf{I}(50.0 \mathrm{mg}, 6.9 \mu \mathrm{mol}), \mathrm{NaOTf}(2.4 \mathrm{mg}, 13.9$ $\mu \mathrm{mol})$ was added, and the resulting solution was stirred for $4 \mathrm{~h}$ at room temperature $\left(\mathrm{ca} .20{ }^{\circ} \mathrm{C}\right)$. Then, diethyl ether $(2.1 \mathrm{~mL})$ was added to the solution, and the solution was filtered off. The brown crystals of II $^{\mathrm{Na}}$ suitable for X-ray crystallographic analysis were obtained after 1 day $(20.9 \mathrm{mg}, 43 \%$ yield based on I). IR ( $\mathrm{KBr}$ pellet): 2962, 2936, 2874, 1162, 1524, 1484, 1463, 1406, 1383, 1269, 1153, 1106, 1017, 962, 938, 890, 790, 757, 634, 539, 386, 372, 333, 308, 297, 291, 281, 278, 267, $254 \mathrm{~cm}^{-1}$; positive ion MS (CSI, acetonitrile): $m / z 3625$ (calcd. 3625.2 ) $\left[\mathrm{TBA}_{7} \mathrm{Si}_{2} \mathrm{~W}_{18} \mathrm{O}_{70} \mathrm{FeMn}_{4} \mathrm{Lu}_{2}(\mathrm{acac})_{4} \mathrm{Na}_{2}\right]^{2+}, 7008$ (calcd. 7008.0) $\left[\mathrm{TBA}_{6} \mathrm{Si}_{2} \mathrm{~W}_{18} \mathrm{O}_{70} \mathrm{FeMn}_{4} \mathrm{Lu}_{2}(\mathrm{acac})_{4} \mathrm{Na}_{2}\right]^{+}$; elemental analysis calcd (\%) for $\mathrm{TBA}_{5}\left[\left(\mathrm{SiW}_{9} \mathrm{O}_{34}\right)_{2} \mathrm{FeMn}_{4} \mathrm{O}_{2}\left\{\mathrm{Lu}(\mathrm{acac})_{2}\right\}_{2} \mathrm{Na}_{2}\right] \cdot 13 \mathrm{H}_{2} \mathrm{O}$ $\left(\mathrm{C}_{100} \mathrm{H}_{234} \mathrm{FeLu}_{2} \mathrm{Mn}_{4} \mathrm{~N}_{5} \mathrm{Na}_{2} \mathrm{O}_{91} \mathrm{Si}_{2} \mathrm{~W}_{18}\right), \mathrm{C}$ 17.16, H 3.37, N 1.00, Si 0.80, W 47.28, Fe 0.80, Mn 3.14, Lu 5.00, Na 0.66; found, C 17.01, H 3.33, N 1.11, Si 0.78, W 47.23, Fe 0.81, Mn 3.08, Lu 5.02, Na 0.63. Synthesis and Characterization of $\mathrm{TBA}_{5}[(\mathrm{~A}-\alpha-$ $\left.\left.\mathrm{SiW}_{9} \mathrm{O}_{34}\right)_{2} \mathrm{FeMn}_{4} \mathrm{O}_{2}\left\{\mathrm{Lu}\left(\mathrm{C}_{5} \mathrm{H}_{7} \mathrm{O}_{2}\right)_{2}\right\}_{2} \mathrm{~K}_{2}\right] \cdot 9 \mathrm{H}_{2} \mathrm{O}\left(\mathrm{II}^{\mathrm{K}}\right)$. To an acetonitrile solution $(1 \mathrm{~mL})$ of $\mathbf{I}(50.0 \mathrm{mg}, 6.9 \mu \mathrm{mol})$, KOTf $(2.6 \mathrm{mg}, 13.9$ $\mu \mathrm{mol})$ was added, and the resulting solution was stirred for $4 \mathrm{~h}$ at room temperature (ca. $\left.20{ }^{\circ} \mathrm{C}\right)$. Then, diethyl ether $(1.5 \mathrm{~mL})$ was added to the solution, and the solution was filtered off. The brown crystals of $\mathrm{II}^{\mathrm{K}}$ suitable for X-ray crystallographic analysis were obtained after 1 day $(25.6 \mathrm{mg}, 53 \%$ yield based on I). IR ( $\mathrm{KBr}$ pellet): $2963,2875,1634,1525,1485,1464,1399,1384,1269,1153,1105$, 1016, 960, 938, 924, 891, 792, 635, 536, 370, 338, 332, 317, 303, 291, 282, 279, $254 \mathrm{~cm}^{-1}$; positive ion MS (CSI, acetonitrile): $\mathrm{m} / z 3641$ (calcd. 3641.4) $\left[\mathrm{TBA}_{7} \mathrm{Si}_{2} \mathrm{~W}_{18} \mathrm{O}_{70} \mathrm{FeMn}_{4} \mathrm{Lu}_{2}(\mathrm{acac})_{4} \mathrm{~K}_{2}\right]^{2+}, 7040$ (calcd. 7040.2) $\left[\mathrm{TBA}_{6} \mathrm{Si}_{2} \mathrm{~W}_{18} \mathrm{O}_{70} \mathrm{FeMn}_{4} \mathrm{Lu}_{2}(\text { acac })_{4} \mathrm{~K}_{2}\right]^{+}$; elemental analysis calcd (\%) for $\mathrm{TBA}_{5}\left[\left(\mathrm{SiW}_{9} \mathrm{O}_{34}\right)_{2} \mathrm{FeMn}_{4} \mathrm{O}_{2}\left\{\mathrm{Lu}(\mathrm{acac})_{2}\right\}_{2} \mathrm{~K}_{2}\right] \cdot 9 \mathrm{H}_{2} \mathrm{O}$ $\left(\mathrm{C}_{100} \mathrm{H}_{226} \mathrm{FeK}_{2} \mathrm{Lu}_{2} \mathrm{Mn}_{4} \mathrm{~N}_{5} \mathrm{O}_{87} \mathrm{Si}_{2} \mathrm{~W}_{18}\right), \mathrm{C}$ 17.26, H 3.27, N 1.01, $\mathrm{Si}$ 0.81, W 47.55, Fe 0.80, Mn 3.16, Lu 5.03, K 1.12; found, C 17.26, H 3.27, N 1.01, Si 0.81, W 47.55, Fe 0.80, Mn 3.16, Lu 5.03, K 1.12.

\section{ASSOCIATED CONTENT}

\section{(s) Supporting Information}

The Supporting Information is available free of charge at https://pubs.acs.org/doi/10.1021/jacs.1c06047.

$\mathrm{X}$-ray crystallographic data, cold-spray ionization mass spectra, electrospray ionization mass spectra, and magnetic data (PDF)

\section{Accession Codes}

CCDC 1570008-1570011 contain the supplementary crystallographic data for this paper. These data can be obtained free of charge via www.ccdc.cam.ac.uk/data request/cif, or by emailing data_request@ccdc.cam.ac.uk, or by contacting The Cambridge Crystallographic Data Centre, 12 Union Road, Cambridge CB2 1EZ, UK; fax: +44 1223336033.

\section{AUTHOR INFORMATION}

\section{Corresponding Authors}

Leroy Cronin - School of Chemistry, The University of Glasgow, Glasgow G12 8QQ, United Kingdom; ○ orcid.org/0000-0001-8035-5757; Email: Lee.Cronin@ glasgow.ac.uk

Kosuke Suzuki - Department of Applied Chemistry, School of Engineering, The University of Tokyo, Bunkyo-ku, Tokyo 113-8656, Japan; Precursory Research for Embryonic Science and Technology (PRESTO), Japan Science and Technology Agency (JST), Kawaguchi, Saitama 332-0012, Japan; ○ orcid.org/0000-0002-8123-1462; Email: ksuzuki@ appchem.t.u-tokyo.ac.jp

\section{Authors}

Takuo Minato - Department of Applied Chemistry, School of Engineering, The University of Tokyo, Bunkyo-ku, Tokyo 113-8656, Japan; School of Chemistry, The University of Glasgow, Glasgow G12 8QQ United Kingdom; Department of Applied Chemistry, Graduate School of Advanced Science and Engineering, Hiroshima University, Higashi-Hiroshima, Hiroshima 739-8527, Japan; ○ orcid.org/0000-00024372-2906

Daniel Salley - School of Chemistry, The University of Glasgow, Glasgow G12 8QQ United Kingdom

Noritaka Mizuno - Department of Applied Chemistry, School of Engineering, The University of Tokyo, Bunkyo-ku, Tokyo 113-8656, Japan

Kazuya Yamaguchi - Department of Applied Chemistry, School of Engineering, The University of Tokyo, Bunkyo-ku, Tokyo 113-8656, Japan; 이이.org/0000-0002-76614936

Complete contact information is available at:

https://pubs.acs.org/10.1021/jacs.1c06047

\section{Notes}

The authors declare no competing financial interest.

\section{ACKNOWLEDGMENTS}

This work was supported in part by JSPS KAKENHI (Grant Numbers JP20H04659, JP17H03037, JP15J09840), JST PRESTO Grant Number JPMJPR18T7, International Network on Polyoxometalate Science at Hiroshima University, the EPSRC-JSPS Core-to-Core program, the EPSRC (Grant Numbers EP/H024107/1, EP/I033459/1, EP/J00135X/1, $\mathrm{EP} / \mathrm{J} 015156 / 1, \mathrm{EP} / \mathrm{K} 021966 / 1, \mathrm{EP} / \mathrm{K} 023004 / 1, \mathrm{EP} /$ $\mathrm{K} 038885 / 1, \mathrm{EP} / \mathrm{L} 015668 / 1, \mathrm{EP} / \mathrm{L} 023652 / 1)$, and the ERC (project 670467 SMART-POM). T.M. was supported by the JSPS through a Research Fellowship for Young Scientists and Overseas Challenge Program for Young Researchers.

\section{REFERENCES}

(1) Feynman, R. P. There's plenty of room at the bottom. Eng. Sci. 1960, 23, 22.

(2) (a) Kang, X.; Li, Y.; Zhu, M.; Jin, R. Atomically precise alloy nanoclusters: syntheses, structures, and properties. Chem. Soc. Rev. 2020, 49, 6443. (b) Ostrowska, M.; Fritsky, I. O.; GumiennaKontecka, E.; Pavlishchuk, A. V. Metallacrown-based compounds: 
Applications in catalysis, luminescence, molecular magnetism, and adsorption. Coord. Chem. Rev. 2016, 327-328, 304. (c) Buchwalter, P.; Rosé, J.; Braunstein, P. Multimetallic catalysis based on heterometallic complexes and clusters. Chem. Rev. 2015, 115, 28. (d) Woodruff, D. N.; Winpenny, R. E. P.; Layfield, R. A. Lanthanide single-molecule magnets. Chem. Rev. 2013, 113, 5110. (e) Kanady, J. S.; Tsui, E. Y.; Day, M. W.; Agapie, T. A synthetic model of the $\mathrm{Mn}_{3} \mathrm{Ca}$ subsite of the oxygen-evolving complex in photosystem II. Science 2011, 333, 733.

(3) (a) Bersuker, I. B. Electronic Structure and Properties of Transition Metal Compounds; Wiley-VHC: Weinheim, Germany, 2010, 238. (b) Magneto-structural Correlations in Exchange Coupled Systems (Eds.: Willett, R. D.; Gatteschi, D.; Kahn, O.), D. Reidel, Dordrecht, 1985, 37.

(4) (a) Tsui, E. Y.; Tran, R.; Yano, J.; Agapie, T. Redox-inactive metals modulate the reduction potential in heterometallic manganese-oxido clusters. Nat. Chem. 2013, 5, 293. (b) Nesterov, D. S.; Kokozay, V. N.; Jezierska, J.; Pavlyuk, O. V.; Boča, R.; Pombeiro, A. J. L. Heterometallic $\mathrm{Cu} / \mathrm{Co}$ and $\mathrm{Cu} / \mathrm{Co} / \mathrm{Zn}$ complexes bearing rare asymmetric tetranuclear cores: Synthesis, structures, and magnetic and catalytic properties toward the peroxidative oxidation of cycloalkanes. Inorg. Chem. 2011, 50, 4401. (c) Fukuda, T.; Biyajima, T.; Kobayashi, N. A discrete quadruple-decker phthalocyanine. J. Am. Chem. Soc. 2010, 132, 6278. (d) Wang, W.-G.; Zhou, A.J.; Zhang, W.-X.; Tong, M.-L.; Chen, X.-M.; Nakano, M.; Beedle, C. C.; Hendrickson, D. N. Giant Heterometallic $\mathrm{Cu}_{17} \mathrm{Mn}_{28}$ Cluster with $\mathrm{T}$ d Symmetry and High-Spin Ground State. J. Am. Chem. Soc. 2007, 129, 1014. (e) Verani, C. N.; Weyhermüller, T.; Rentschler, E.; Bill, E.; Chaudhuri, P. A rational assembly of a series of exchange coupled linear heterotrinuclear complexes of the type MAMBMC as exemplified by $\mathrm{Fe}^{\mathrm{III}} \mathrm{Cu}^{\mathrm{II}} \mathrm{Ni}^{\mathrm{II}}, \mathrm{Fe}^{\mathrm{III}} \mathrm{Ni}^{\mathrm{II}} \mathrm{Cu}^{\mathrm{II}}$ and $\mathrm{Co}^{\mathrm{III}} \mathrm{Cu}^{\mathrm{II}} \mathrm{Ni}^{\mathrm{II}}$. Chem. Commun. 1998, 2475.

(5) (a) Mahapatra, P.; Ghosh, S.; Giri, S.; Rane, V.; Kadam, R.; Drew, M. G. B.; Ghosh, A. Subtle structural changes in $\left(\mathrm{Cu}^{\mathrm{II}} \mathrm{L}\right)_{2} \mathrm{Mn}^{\mathrm{II}}$ complexes to induce heterometallic cooperative catalytic oxidase activities on phenolic substrates $\left(\mathrm{H}_{2} \mathrm{~L}=\right.$ Salen type unsymmetrical schiff base). Inorg. Chem. 2017, 56, 5105. (b) Yang, X.; Chan, C.; Lam, D.; Schipper, D.; Stanley, J. M.; Chen, X.; Jones, R. A.; Holliday, B. J.; Wong, W.-K.; Chen, S.; Chen, Q. Anion-dependent construction of two hexanuclear $3 \mathrm{~d}-4 \mathrm{f}$ complexes with a flexible Schiff base ligand. Dalton Trans. 2012, 41, 11449. (c) Sasmal, S.; Majumder, S.; Hazra, S.; Sparkes, H. A.; Howard, J. A. K.; Nayak, M.; Mohanta, S. Tetrametallic $[2 \times 1+1 \times 2]$, octametallic double-decker-tripledecker $[5 \times 1+3 \times 1]$, hexametallic quadruple-decker and dimetallicbased one-dimensional complexes of copper (ii) and s block metal ions derived from $N, N^{\prime}$-ethylenebis(3-ethoxysalicylaldimine). CrystEngComm 2010, 12, 4131.

(6) (a) Peng, Y.; Powell, A. K. What do 3d-4f butterflies tell us? Coord. Chem. Rev. 2021, 426, 213490. (b) Liu, K.; Shi, W.; Cheng, P. Toward heterometallic single-molecule magnets: Synthetic strategy, structures and properties of $3 \mathrm{~d}-4 \mathrm{f}$ discrete complexes. Coord. Chem. Rev. 2015, 289-290, 74.

(7) (a) Adv. Inorg. Chem., ed. by Eldik, R.; Cronin, L. Elsevier Academic Press, Amsterdam, 2017, Vol. 69, 1. (b) Polyoxometalate Chemistry for Nano-Composite Design, ed. by Yamase, T.; Pope, M. T. Kluwer Academic/Plenum Publishers, New York, 2002, 197. (c) Song, Y.-F.; Tsunashima, R. Recent advances on polyoxometalate-based molecular and composite materials. Chem. Soc. Rev. 2012, 41, 7384. (d) Streb, C. New trends in polyoxometalate photoredox chemistry: From photosensitisation to water oxidation catalysis. Dalton Trans. 2012, 41, 1651. (e) Lv, H.-J.; Geletii, Y. V.; Zhao, C.C.; Vickers, J. W.; Zhu, G.-B.; Luo, Z.; Song, J.; Lian, T.-Q.; Musaev, D. G.; Hill, C. L. Polyoxometalate water oxidation catalysts and the production of green fuel. Chem. Soc. Rev. 2012, 41, 7572. (f) Wang, S.S.; Yang, G.-Y. Recent advances in polyoxometalate-catalyzed reactions. Chem. Rev. 2015, 115, 4893. (g) Weinstock, I. A.; Schreiber, R. E.; Neumann, R. Dioxygen in polyoxometalate mediated reactions. Chem. Rev. 2018, 118, 2680. (h) Suzuki, K.; Mizuno, N.; Yamaguchi, K. Polyoxometalate photocatalysis for liquid-phase selective organic functional group transformations. ACS Catal. 2018, $8,10809$.

(8) (a) Oms, O.; Dolbecq, A.; Mialane, P. Diversity in structures and properties of 3d-incorporating polyoxotungstates. Chem. Soc. Rev. 2012, 41, 7497. (b) Shiddiq, M.; Komijani, D.; Duan, Y.; Gaita-Ariño, A.; Coronado, E.; Hill, S. Enhancing coherence in molecular spin qubits via atomic clock transitions. Nature 2016, 531, 348. (c) Kamata, K.; Yonehara, K.; Nakagawa, Y.; Uehara, K.; Mizuno, N. Efficient stereo-and regioselective hydroxylation of alkanes catalysed by a bulky polyoxometalate. Nat. Chem. 2010, 2, 478. (d) Sadakane, M.; Steckhan, E. Electrochemical properties of polyoxometalates as electrocatalysts. Chem. Rev. 1998, 98, 219.

(9) (a) Sato, R.; Suzuki, K.; Minato, T.; Shinoe, M.; Yamaguchi, K.; Mizuno, N. Field-induced slow magnetic relaxation of octahedrally coordinated mononuclear Fe (III)-, Co (II)-, and Mn (III)-containing polyoxometalates. Chem. Commun. 2015, 51, 4081. (b) Suzuki, K.; Sato, R.; Minato, T.; Shinoe, M.; Yamaguchi, K.; Mizuno, N. A cascade approach to hetero-pentanuclear manganese-oxide clusters in polyoxometalates and their single-molecule magnet properties. Dalton Trans. 2015, 44, 14220. (c) Sato, R.; Suzuki, K.; Minato, T.; Yamaguchi, K.; Mizuno, N. Sequential Synthesis of $3 d-3 d^{\prime}-4 f$ Heterometallic Heptanuclear Clusters in between Lacunary Polyoxometalates. Inorg. Chem. 2016, 55, 2023. (d) Minato, T.; Suzuki, K.; Ohata, Y.; Yamaguchi, K.; Mizuno, N. A modular synthesis approach to multinuclear heterometallic oxo clusters in polyoxometalates. Chem. Commun. 2017, 53, 7533. (e) Minato, T.; Ohata, Y.; Ishii, K.; Yamaguchi, K.; Mizuno, N.; Suzuki, K. Exploring orientationally aligned anisotropic large spin molecules with unusual long-distance intermolecular ferromagnetic interactions. J. Mater. Chem. C 2019, 7, 12918. (f) Yonesato, K.; Ito, H.; Itakura, H.; Yokogawa, D.; Kikuchi, T.; Mizuno, N.; Yamaguchi, K.; Suzuki, K. Controlled assembly synthesis of atomically precise ultrastable silver nanoclusters with polyoxometalates. J. Am. Chem. Soc. 2019, 141, 19550. (g) Minato, T.; Suzuki, K.; Yamaguchi, K.; Mizuno, N. Synthesis and Disassembly/ Reassembly of Giant Ring-Shaped Polyoxotungstate Oligomers. Angew. Chem., Int. Ed. 2016, 55, 9630.

(10) (a) de la Oliva, A. R.; Sans, V.; Miras, H. N.; Yan, J.; Zang, H.; Richmond, C. J.; Long, D.-L.; Cronin, L. Assembly of a gigantic polyoxometalate cluster $\left\{\mathrm{W}_{200} \mathrm{Co}_{8} \mathrm{O}_{660}\right\}$ in a networked reactor system. Angew. Chem., Int. Ed. 2012, 51, 12759. (b) Richmond, C. J.; Miras, H. N.; de la Oliva, A. R.; Zang, H.; Sans, V.; Paramonov, L.; Makatsoris, C.; Inglis, R.; Brechin, E. K.; Long, D.-L.; Cronin, L. A flow-system array for the discovery and scale up of inorganic clusters. Nat. Chem. 2012, 4, 1037. (c) Zang, H.-Y.; de la Oliva, A. R.; Miras, H. N.; Long, D.-L.; McBurney, R. T.; Cronin, L. Discovery of gigantic molecular nanostructures using a flow reaction array as a search engine. Nat. Commun. 2014, 5, 3715. (d) Duros, V.; Grizou, J.; Xuan, W.; Hosni, Z.; Long, D.-L.; Miras, H. N.; Cronin, L. Human versus robots in the discovery and crystallization of gigantic polyoxometalates. Angew. Chem., Int. Ed. 2017, 56, 10815. (e) Lehmann, J. W.; Blair, D. J.; Burke, M. D. Towards the generalized iterative synthesis of small molecules. Nat. Rev. Chem. 2018, 2, 0115. (f) Granda, J.; Donia, L.; Dragone, V.; Long, D.-L.; Cronin, L. Controlling an organic synthesis robot with machine learning to search for new reactivity. Nature 2018, 559, 377. (g) Steiner, S.; Wolf, J.; Glatzel, S.; Andreou, A.; Granda, J.; Keenan, G.; Hinkley, T.; Aragon-Camarasa, G.; Kitson, P. J.; Angelone, D.; Cronin, L. Organic synthesis in a modular robotic system driven by a chemical programming language. Science 2019, 363, eaav2211. (h) Salley, D.; Keenan, G.; Grizou, J.; Sharma, A.; Martín, S.; Cronin, L. A nanomaterials discovery robot for the Darwinian evolution of shape programmable gold nanoparticles. Nat. Commun. 2020, 11, 2771.

(11) Salley, D.; Keenan, G. A.; Long, D.-L.; Bell, N. L.; Cronin, L. A modular programmable inorganic cluster discovery robot for the discovery and synthesis of polyoxometalates. ACS Cent. Sci. 2020, 6, 1587.

(12) Minato, T.; Suzuki, K.; Kamata, K.; Mizuno, N. Synthesis of $\alpha$ Dawson-Type Silicotungstate $\left[\alpha-\mathrm{Si}_{2} \mathrm{~W}_{18} \mathrm{O}_{62}\right]^{8-}$ and Protonation and 
Deprotonation Inside the Aperture through Intramolecular Hydrogen Bonds. Chem. - Eur. J. 2014, 20, 5946.

(13) (a) Zhang, D.; Cao, F.; Ma, P.; Zhang, C.; Song, Y.; Liang, Z.; $\mathrm{Hu}, \mathrm{X}$.; Wang, J.; Niu, J. A $\left\{\mathrm{Nb}_{6} \mathrm{P}_{2} \mathrm{~W}_{12}\right\}$-Based Hexameric Manganese Cluster with Single-Molecule Magnet Properties. Chem. - Eur. J. 2015, 21, 17683. (b) Ibrahim, M.; Lan, Y.; Bassil, B. S.; Xiang, Y.; Suchopar, A.; Powell, A. K.; Kortz, U. Hexadecacobalt (II)-containing polyoxometalate-based single-molecule magnet. Angew. Chem., Int. Ed. 2011, 50, 4708. (c) Ibrahim, M.; Haider, A.; Lan, Y.; Bassil, B. S.; Carey, A. M.; Liu, R.; Zhang, G.; Keita, B.; Li, W.; Kostakis, G. E.; Powell, A. K.; Kortz, U. Multinuclear cobalt (II)-containing heteropolytungstates: structure, magnetism, and electrochemistry. Inorg. Chem. 2014, 53, 5179. (d) Fang, X.; McCallum, K.; Pratt, H. D., III; Anderson, T. M.; Dennis, K.; Luban, M. A co-crystal of polyoxometalates exhibiting single-molecule magnet behavior: the structural origin of a large magnetic anisotropy. Dalton Trans. 2012, 41, 9867. (e) Zhang, Z.-M.; Yao, S.; Li, Y.-G.; Wu, H.-H.; Wang, Y.H.; Rouzières, M.; Clérac, R.; Su, Z.-M.; Wang, E.-B. A polyoxometalate-based single-molecule magnet with a mixed-valent $\left\{\mathrm{Mn}_{2}^{\mathrm{IV}} \mathrm{Mn}_{6}^{\mathrm{III}} \mathrm{Mn}_{4}^{\mathrm{II}}\right\}$ core. Chem. Commun. 2013, 49, 2515.

(14) (a) CrystalClear 1.3.6, Rigaku and Rigaku/MSC, The Woodlands, TX. (b) Pflugrath, J. W. Acta Crystallogr., Sect. D: Biol. Crystallogr. 1999, D55, 1718.

(15) Rigaku OD CrysAlis PRO. Rigaku Oxford Diffraction Ltd, Yarnton, England,(2018).

(16) CrystalStructure 3.8, Rigaku and Rigaku/MSC, TheWoodlands, TX.

(17) Farrugia, L. J. WinGX suite for small-molecule single-crystal crystallography. J. Appl. Crystallogr. 1999, 32, 837.

(18) (a) Sheldrick, G. M. A short history of SHELX. Acta Crystallogr., Sect. A: Found. Crystallogr. 2008, A64, 112-122. (b) Sheldrick, G. M. Crystal structure refinement with SHELXL. Acta Crystallogr., Sect. C: Struct. Chem. 2015, C71, 3-8.

(19) van der Sluis, P.; Spek, A. L. BYPASS: an effective method for the refinement of crystal structures containing disordered solvent regions. Acta Crystallogr., Sect. A: Found. Crystallogr. 1990, A46, 194.

(20) (a) Brown, I. D.; Altermatt, D. Bond-valence parameters obtained from a systematic analysis of the Inorganic Crystal Structure Database. Acta Crystallogr., Sect. B: Struct. Sci. 1985, B41, 244. (b) Brese, N. E.; O'Keeffe, M. Bond-valence parameters for solids. Acta Crystallogr., Sect. B: Struct. Sci. 1991, B47, 192. 